\title{
Optimal Active Energy Loss with Feeder Routing and Renewable Energy for Smart Grid Distribution
}

\author{
Phatcharasak Phawanaphinyo, Narongdech Keeratipranon * and \\ Chaiyaporn Khemapatapan
}

\author{
College of Innovative Technology and Engineering, Dhurakij Pundit University, Bangkok, Thailand
}

\begin{abstract}
Electric power is the main energy source for a modern society. Good management of electric power cycle is essential for a sustainable society. The electric power cycle is composed of Generation, Transmission, Distribution, and Consumption. Smart Grid (SG) is a system that integrated traditional grids with Information and Communication Technology (ICT). In addition, SG has the ability to integrate electrical power supply from both to main power substation and Distributed Generation (DG), which compensates for the power demand during peak times. However, SG still has a similar problem to the original grid in terms of active power loss, from electric current injecting through the transmission line. This paper solves the active power loss problem by feeder routing using the Adjusting Dijkstra's Cost Method, follow by deciding the allocation position and sizing of DG by the use of Evolutionary Computing, namely Harmony Search (HS), Artificial Bee Colony (ABC), and Particle Swarm Optimization (PSO). The experiments evaluate the performance of the algorithm using power flow analysis, Backward / Forward Sweep Method, on the IEEE 33 bus system. From the experimental results, PSO provides the best performance. The overall active power loss in the cases of 3 DGs was reduced from 202.67 to $52.29 \mathrm{~kW}$, representing a reduction of $74.20 \%$.
\end{abstract}

Keywords: Minimal active power loss, Backward / Forward Sweep Method, Harmony Search, Artificial Bee Colony, Particle Swarm Optimization.

\section{INTRODUCTION}

A smart electricity system, such as a Smart Grid (SG) system, is required in order to efficiently serve higher power demand. The SG is an integration between a traditional grid and Information and Communication Technology (ICT). SG covers from the processes of Generation, Transmission, Distribution, to Consumption. In addition, from power plant electric sourcing, SG must be able to manage an extra power source from a Distributed Generation (DG). Although the SG distribution has more advanced information, it still suffers from the same problem as the traditional grid, namely active power loss, that affects the electrical power transfer directly. The problem above was leading to significant funds to improve the distribution line, distribution transformer, and substation building to accommodate active power loss (Huang et al., 2014).

In related research, the defined radial distribution feeder routing with Dijkstra's algorithm reduces the fixed cost, energy cost, and interruption cost (Jha and Vidyasagar, 2013). In DG allocation and sizing, Harmony Search (HS) was used to solve the problem. The objective was to allocate DG such that the voltage profile of the overall system is stable. The experiments

*Address of correspondence to this author at the College of Innovative Technology and Engineering, Dhurakij Pundit University, Bangkok, Thailand; Tel: +66 2954-7300; Fax: +66 2954-7356; E-mail: narongdech.ken@dpu.ac.th JEL: C53, C55, C61, Q21. using the IEEE 33 bus and IEEE 69 bus system compared the results with the Genetic Algorithm (GA) and Refine Genetic Algorithm (RGA). The results showed HS was the most efficient in term of processing time (Rao et al., 2013). The Particle Swarm Optimization (PSO) was used to determine the allocation and sizing of the DG to reduce the active power loss. In the experiments with the IEEE 33 bus system, the results reduced active power loss by determining the allocation and sizing of the DG appropriately (Guerriche and Boktir, 2015). The Artificial Bee Colony (ABC) was successfully applied to minimize the active power loss with the IEEE 33 bus and IEEE 69 bus system. The results in the modified $A B C$ can reduce processing time and number of iterations in the process (Fahad and Mohamed, 2009).

In order to minimize active power loss, this paper selects the IEEE 33 bus system and processes with feeder routing. After defined the routing path, the DG allocation and sizing was used to compare the techniques of $\mathrm{HS}, \mathrm{ABC}$, and PSO. The overall solutions are shown in Figure 1.

\section{PROPOSED METHODOLOGY}

\subsection{Topology Model}

The IEEE 33 bus system is used as experimental data in this paper (Baran and Wu, 1989). The structure is composed of two main parts, nodes and branches. Node (in power electric distribution called node as a 


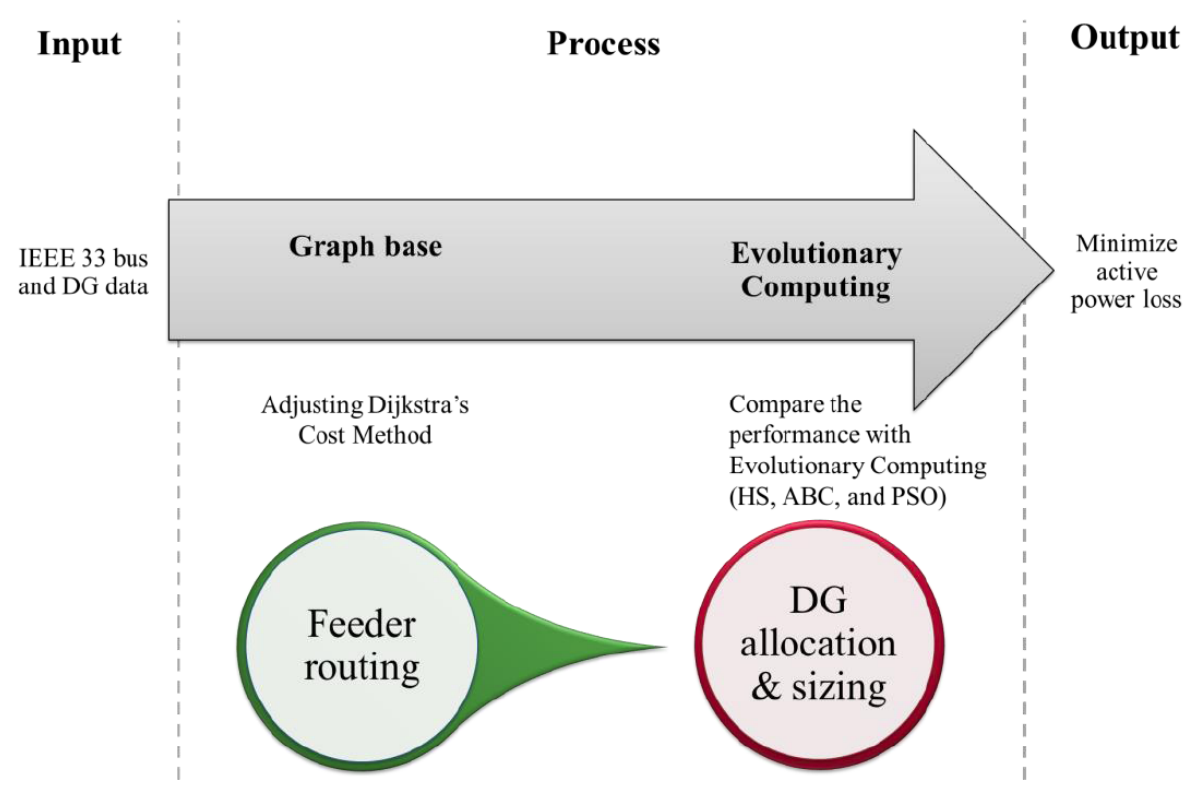

Figure 1: Overview of Solution.

a. IEEE 33 Bus System (Source: Tolabi et al., 2015)

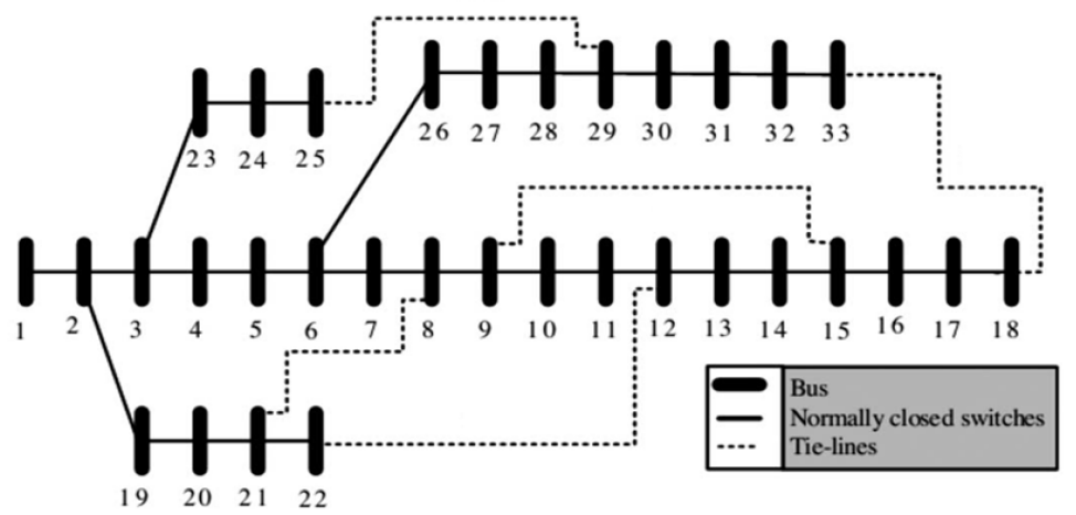

b. Graph Base Topology from IEEE 33 Bus System

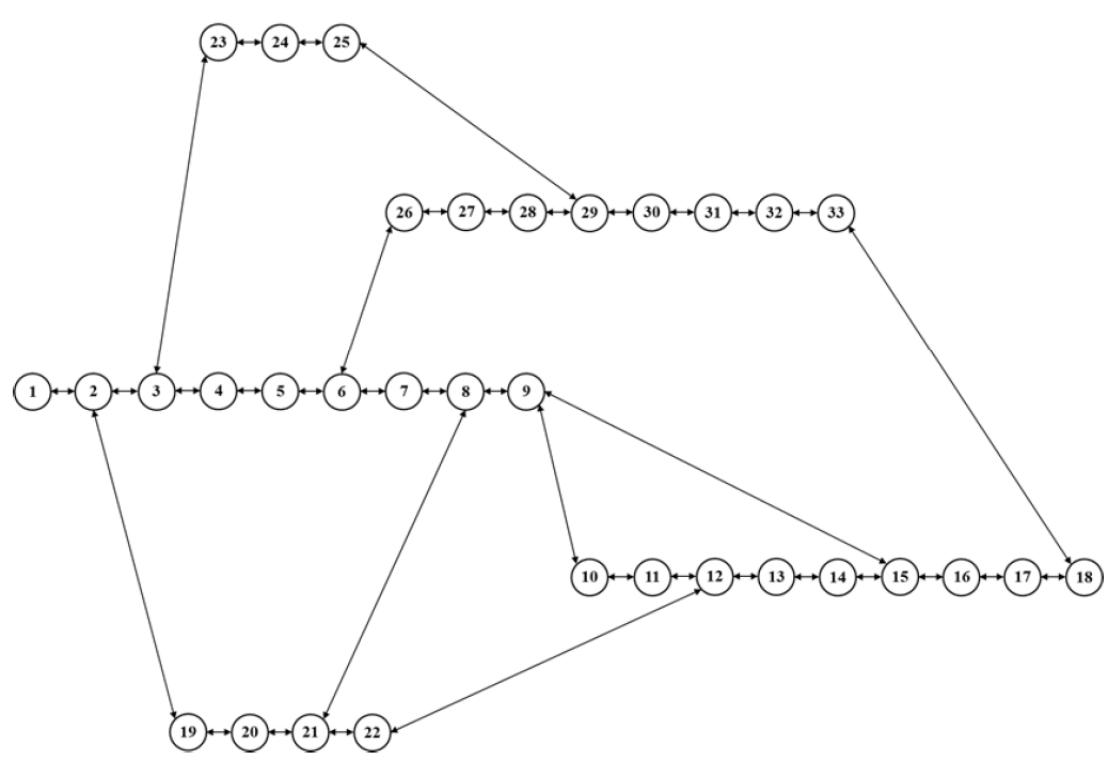

Figure 2: IEEE 33 Bus System. 
Table 1: IEEE 33 Bus Data

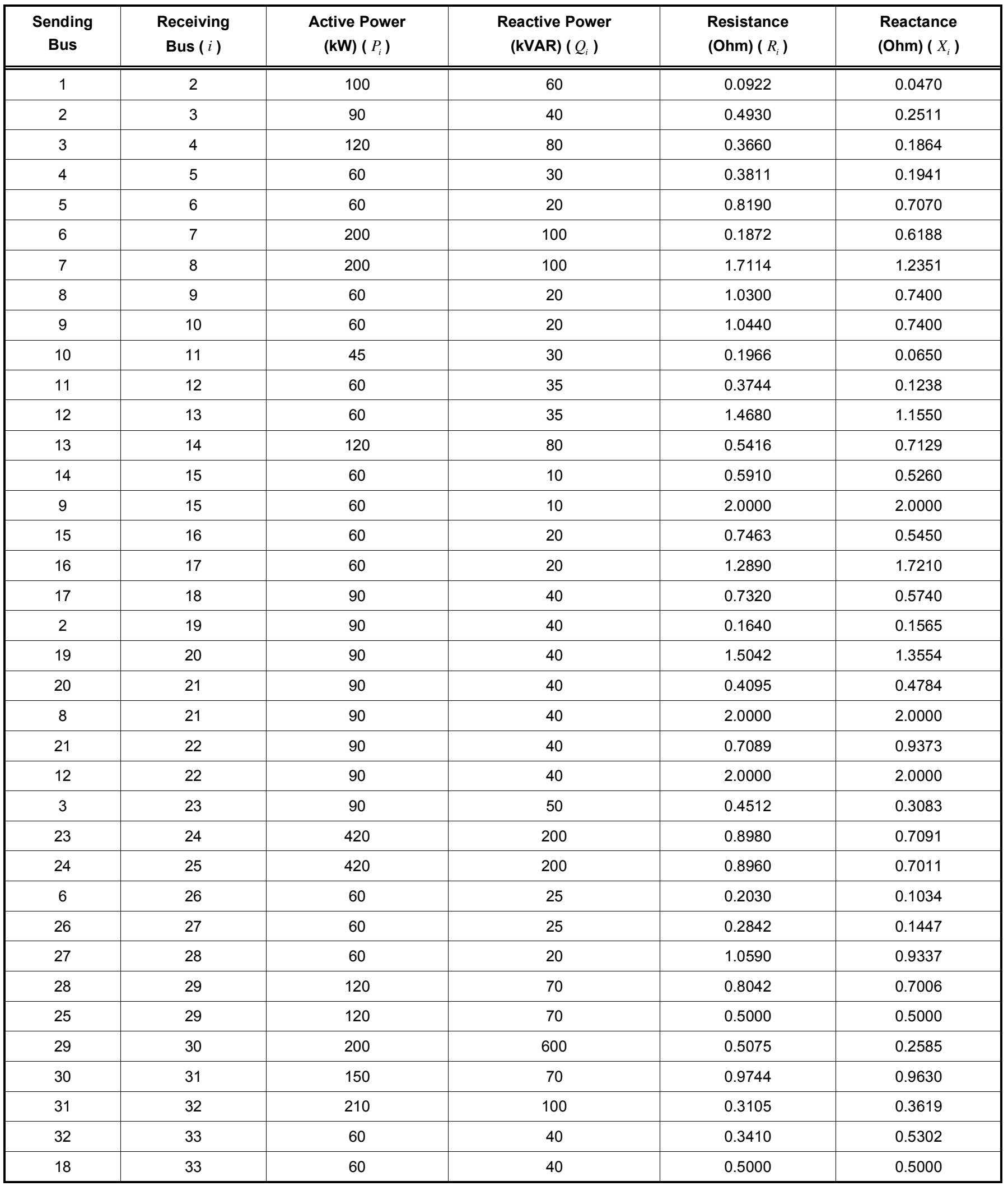

bus) can be further grouped into power source (slack bus) and consumption unit (load bus) represented by a circle, as shown in Figure 2. The branch is represented by the directed line showing a flow in the power system. The main characteristics for each bus were composed of two static variables, Active Power $\left(P_{i}\right)$ 
measured in Watt and Reactive Power $\left(Q_{i}\right)$ the unit as VAR. The two main characteristics of branches are Resistance $\left(R_{i}\right)$ and Reactance $\left(X_{i}\right)$ the unit as Ohm, as shown in Table 1.

\subsection{Adjusting Dijkstra's Cost Method}

Dijkstra's algorithm had been determined to choose the shortest path from a source bus to a destination. The shortest distance was calculated from the explicit cost in the graph. For the power routing, when the route changed, the voltage and current implied changed accordingly. Therefore, the power routing remained difficult to determine the routing cost. As a result, the feeder routing still has a trouble in finding the exact current used as a weight to each edge in the graph.

This paper devises a feeder routing method with Dijkstra's algorithm for determining the cost to solve the problem. The method has the ability to adjust cost according to the direction of the power flow, where cost is calculated from the power flow method. The calculation is repeated until the power variables are stable. The step of Adjusting Dijkstra's Cost Method, as shown in Figure 3, was composed of:
Step (1): Calculate routing cost. Define the initial values of $I_{K C L, i, t}$ equal to $\infty$, and calculate the weight, current, in the graph as:

$$
C_{i, t}=\tan ^{-1} \frac{I_{K V L, i, t}^{2} * X_{i}}{I_{K V L, i, t}^{2} * R_{i}}
$$

where $C_{i, t}$ is the cost of the branch, connecting two nodes, where $i$ represents in flow current of bus number $i$ at time $t$, which is calculated by the arctan of the ratio between $I_{K V L, i, t}^{2} * X_{i}$ and $I_{K V L, i, t}^{2} * R_{i}$.

Step (2): Dynamic feeder routing process (Dijkstra's algorithm). Dijkstra's algorithm was modified by separation for routing as the process:

(2.1) Finds the shortest path with Dijkstra's algorithm, the process of finding the shortest path from one source to all destinations.

(2.2) Cuts duplicate branches by cutting the overlapping branches.

(2.3) Eliminates the multi-source bus by selecting the bus with the lowest total cost to the source bus, with others cut off.

(1) Calculate routing cost

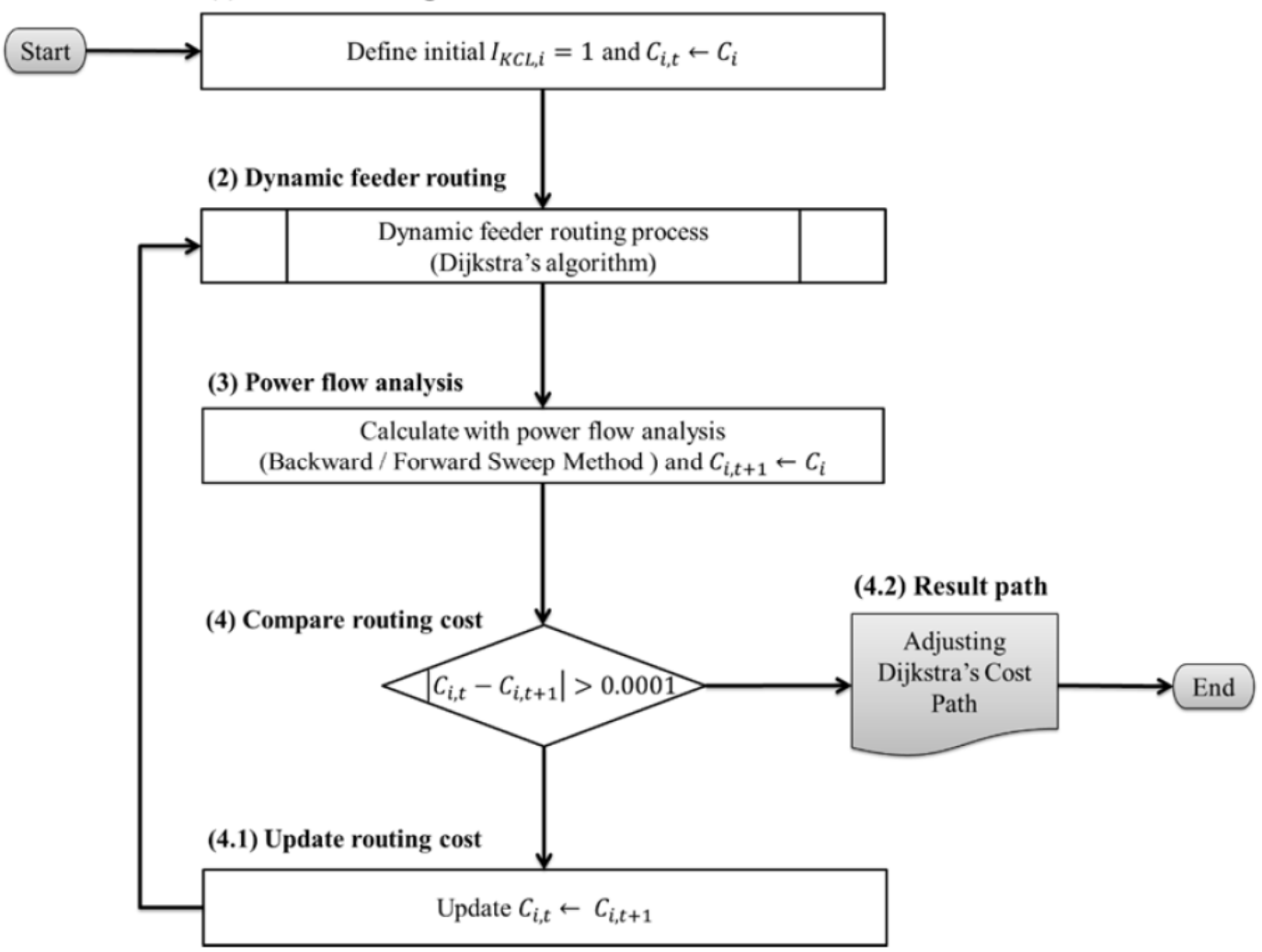

Figure 3: Adjusting Dijkstra's Cost Method. 
(2.4) Moves the end bus to compare active power loss so the results can be separated into two cases. If the bus is moved and active power loss is reduced, (2.4.1) moves the end bus to the minimal active power loss source bus. Recursive analysis of the process (2.3) until active power loss cannot be minimized further. The final result is called the Adjusting Dijkstra's Cost path (2.4.2).

Step (3): Power flow analysis. The power flow parameters calculate the new current in time period $t+1$, in terms of $I_{K C L, i, t+1}$ for the purpose of adjusting the new cost in terms of $C_{i, t+1}$.

Step (4): Compare routing cost between $C_{i, t+1}$ and $C_{i, t}$. In the comparison, if the tolerance is greater than or equal to 0.0001 , go to step (4.1), otherwise go to step (4.2).

(4.1) The cost is adjusted by $C_{i, t+1}$ and is repeated from the second step.

(4.2) The result will be the lower active power loss path with the right cost. In the process, update the new cost so that the improvement will replace the higher cost. According to Dijkstra's algorithm, routing to the lowest cost, the branches will be chosen and the cost is improved. The shortest path is defined as the actual cost.

\subsection{Problem Formulation}

As the active power loss depends on the current that is injected through the branch, as calculated by Ohm's Law, the installation of DG changes the active power and the current. Accordingly, the objective function the active power loss, is defined as follows:

Minimize $\sum_{i=1}^{n} I_{K C L, i}^{2} R_{i}$,

where $I_{K C L, i}$ is the current (Ampere) of the branch that is injected into bus number $i$, which can be calculated by the power flow method, and $R_{i}$ is the resistance of the branch that flows into bus number $i$. The constraints in the experiment are included as the parameters of the bus and branch that are composed of current, voltage, active power, reactive power, and appearance power:

$$
\begin{aligned}
& I_{K C L, i, t+1} \leq I_{i}^{\max }, \\
& V_{i}^{\min } \leq V_{K V L, i} \leq V_{i}^{\max },
\end{aligned}
$$

where $I_{K C L, i}$ is the current (Ampere) that is limited to not more than $I_{M A X, i}$, under the condition of the maximum current flow in conductor type in branch $i$. The voltage level of the bus must not be at a higher or lower voltage limit, and the lower and upper limits of the voltage security range are set to be 0.90 and 1.05 per-unit (p.u.) value. (Alafnan et al., 2016). $V_{K V L, i}$ is the voltage (Volt) in bus number $i$, with value not less than $V_{i}^{\min }$ and not more than $V_{i}^{\max }$. The active power and reactive power produced from DG must be the limit of the bus. The constraints are shown follows:

$$
\begin{aligned}
& P_{D G, i}^{\min } \leq P_{D G, i} \leq P_{D G, i}^{\max }, \\
& Q_{D G, i}^{\min } \leq Q_{D G, i} \leq Q_{D G, i}^{\max },
\end{aligned}
$$

where $P_{D G, i}$ is the active power (Watt) in bus number $i$ that supplies power in the range $P_{D G, i}^{\min }$ and $P_{D G, i}^{\max }$. Similarly, $Q_{D G, i}$ is the reactive power (VAR) in bus number $i$ that supplies power in the range $Q_{D G, i}^{\min }$ and $Q_{D G, i}^{\max }$ Moreover, the appearance power must not exceed the power requirement in all buses, which can be shown as:

$\sum_{i=1}^{i} \sqrt{P_{D G, i}^{2}+Q_{D G, i}^{2}} \leq \sum_{i=1}^{i} \sqrt{P_{\text {Load }, i}^{2}+Q_{\text {Load }, i}^{2}}$,

where equation (7) represents that all the appearance power generated from DG must not be more than the all required appearance power on the bus.

\section{SIMULATION RESULTS}

The experiment to minimize active power loss was divided into two steps. The first was feeder routing with Adjusting Dijkstra's Cost method, and the second is the DG allocation and sizing with Evolutionary Computing. The Evolutionary Computing methods, HS, ABC, and PSO are compared. The standard model, the IEEE 33 bus system, was chosen and defined, the voltage base was $12.66 \mathrm{kV}$, and the apparent power base was 10 MVA.

\subsection{Feeder Routing with Adjusting Dijkstra's Cost Method}

The accuracy in the calculation of active power loss can be verified by routing by opening the tie switches between buses $8-21,9-15,12-22,18-33$, and 25-29. All the active power and reactive power were equal to $3,715.00 \mathrm{~kW}$ and $2,300.00 \mathrm{kVAR}$, respectively. In the test of routing with the base path, the power loss was $202.67 \mathrm{~kW}$, and as accurate as other available results 
(Abdel-Akher, 2013; Esmaeilian and Fadaeinedjad, 2015; Jena and Chauhan, 2016). After verifying the accuracy, the next step was Adjusting Dijkstra's Cost method. The feeder routing can be routed to the lower active power path with adjusted $C_{i, t}$ in 4 iterations. The topology form the lower active power loss path was changed by opening the switch between buses 7-8, 9$10,14-15,25-29$ and $32-33$. The results show that the decision of Adjusting Dijkstra's Cost method has reduced active power loss to $139.56 \mathrm{~kW}$, as shown in Figure 4.

\subsection{DG Allocation and Sizing}

In this part, three evolutional algorithms, HS, ABC, and $\mathrm{PSO}$, are used as the technique to solve the DG allocation and sizing challenge. The initial topology was obtained from the Adjusting Dijkstra's Cost path result, as explained in the previous section. The number of load buses in the graph, 32 in this case, were used as the problem dimension. The analysis consisted of 4 cases, Case-I: 1 DG with the maximum supply 1,000.00 kW; Case-II: 1 DG with maximum supply 2,000.00 kW; Case-III: 2 DGs with maximum supply $1,000.00 \mathrm{~kW}$; and Case-IV: 3 DGs with maximum supply $1,000.00 \mathrm{~kW}$. At the first stage, Case-I and Case-Il were used to compare the results to find the appropriate method between $\mathrm{HS}, \mathrm{ABC}$, and PSO (Aswini and Seshu, 2016; Priya and Reddy, 2013; Farhadi et al., 2013).

The parameters of the HS were composed of: Vector of Harmony Size (HMS) was 32, Harmony Memory (HM) was 30, Harmony Consideration Rate
(HCR) was 0.9, Pitch Adjust Rate (PAR) was 0.3, and Bandwidth $(b w)=0.01$. The parameters of the $A B C$ were set as follows: the nectar source was 32 , scout bees were 70 , employed bees were 35 , and onlooker bees were 35 . Similarly, the parameters of the PSO were composed of the problem dimensions equal to 32 , the inertia weight equal to 0.3 , the swarm size equal to 100 , and the learning factors $a_{1}$ and $a_{2}$ equal to 1.5 .

All the methods were processed until the termination condition was found. The best cost does not change more than the tolerance, 0.0001 , in the 100-previous rounds. The experimentation for each case was repeated 10 times. The results from each algorithm was compared using many criteria, including power loss (best cost), bus allocation, DG sizing, optimal iterations, and optimal processing time. The results were compared in terms of the mean and standard deviation $(\sigma)$ values, are shown Table 2.

In Case-I, all methods connected DG on bus 30 . The HS defined the mean active power nearly optimal capacity $(1,000.00 \mathrm{~kW})$, while $A B C$ and PSO can be implemented to the maximum DG capacity. In terms of reducing active power loss, $\mathrm{ABC}$ and $\mathrm{PSO}$ can reduce active power loss equal to $92.68 \mathrm{~kW}(\sigma=0.0000)$. The $\mathrm{HS}$ reduced the mean active power loss to $93.15 \mathrm{~kW}$ $(\sigma=0.4443)$. The optimal iteration and processing time of HS had average 82.33 cycles $(\sigma=14.3233)$ and 7.08 seconds $(\sigma=1.2501)$, respectively. The results from the $A B C$ and PSO were similar. The active power losses in both algorithms were optimal, with best cost at $92.68 \mathrm{~kW}(\sigma=0.0000)$, and DG sizing presented as $1,000.00 \mathrm{~kW}(\sigma=0.0000)$.

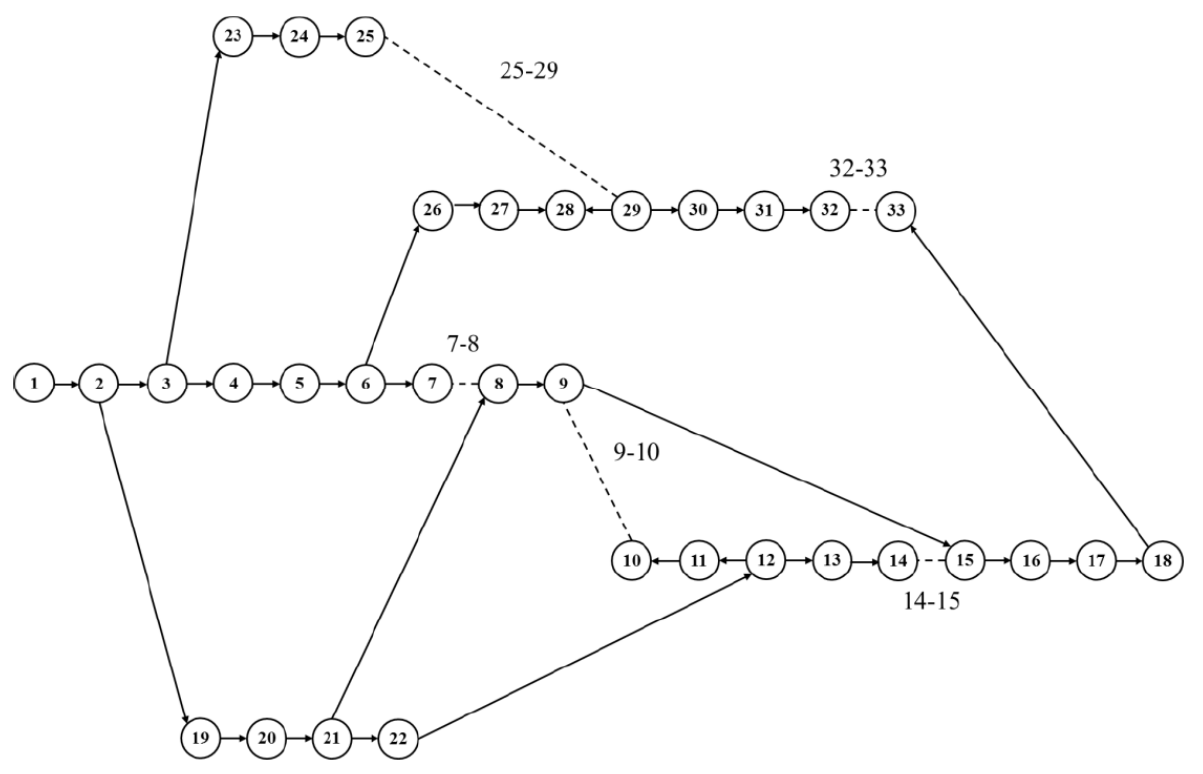

Figure 4: Adjusting Dijkstra's Cost Path. 
Table 2: Comparison of $\mathrm{HS}, \mathrm{ABC}$, and PSO

\begin{tabular}{|c|c|c|c|c|c|c|}
\hline \multirow{2}{*}{ Indicators } & \multicolumn{6}{|c|}{ Algorithms } \\
\hline & Mean & $\sigma$ & Mean & $\sigma$ & Mean & $\sigma$ \\
\hline \multicolumn{7}{|c|}{ Case-I: DG allocation bus [30] } \\
\hline Power loss (kW) & 93.15 & 0.4443 & 92.68 & 0.0000 & 92.68 & 0.0000 \\
\hline Optimal iteration (cycles) & 82.33 & 14.3233 & 3.56 & 1.4181 & 2.00 & 0.0000 \\
\hline Optimal processing time (seconds) & 7.08 & 1.2501 & 11.84 & 4.5420 & 1.59 & 0.0564 \\
\hline \multicolumn{7}{|c|}{ Case-II: DG allocation bus [25] } \\
\hline Active power loss (kW) & 85.41 & 0.1835 & 84.97 & 0.0000 & 84.97 & 0.0000 \\
\hline Optimal processing time (seconds) & 47.44 & 2.2555 & 318.75 & 69.9454 & 42.00 & 7.7876 \\
\hline
\end{tabular}

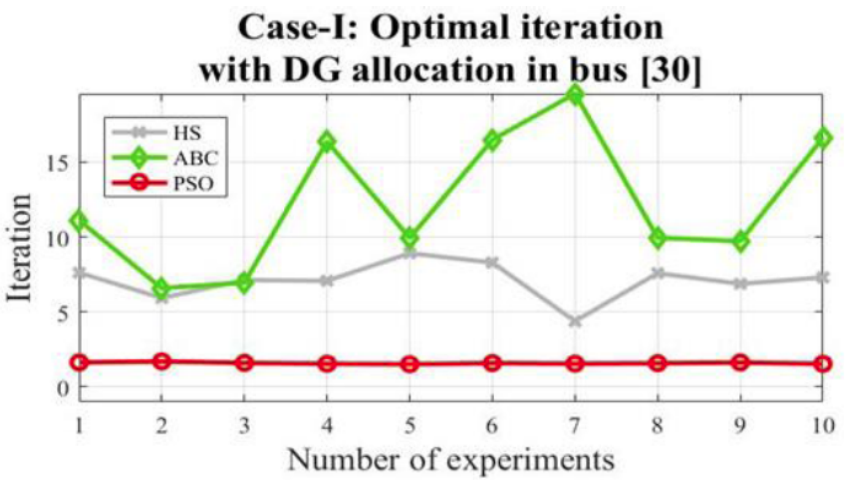

Case-I: Optimal processing time with DG allocation in bus [30]

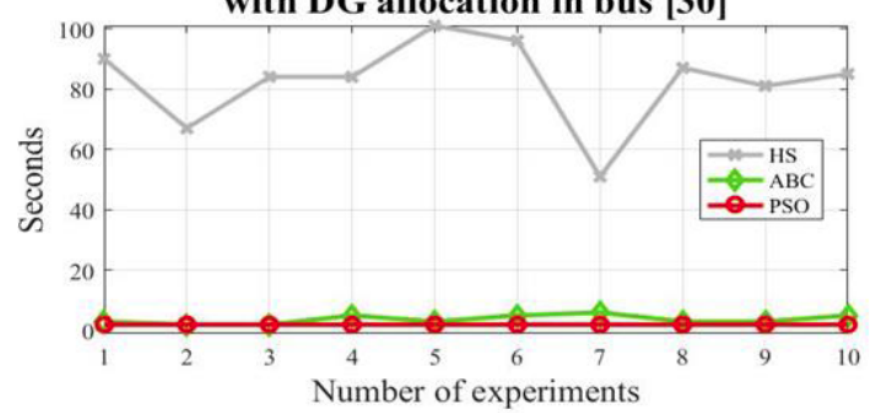

Case-II: Optimal iteration with DG allocation in bus [25]

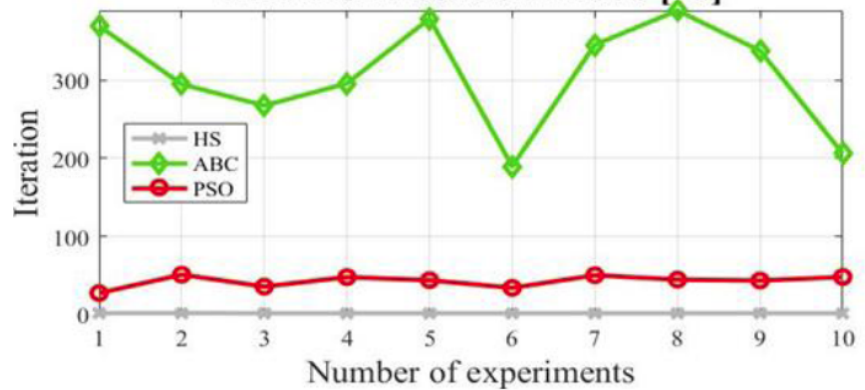

Case-II: Optimal processing time with DG allocation in bus [25]

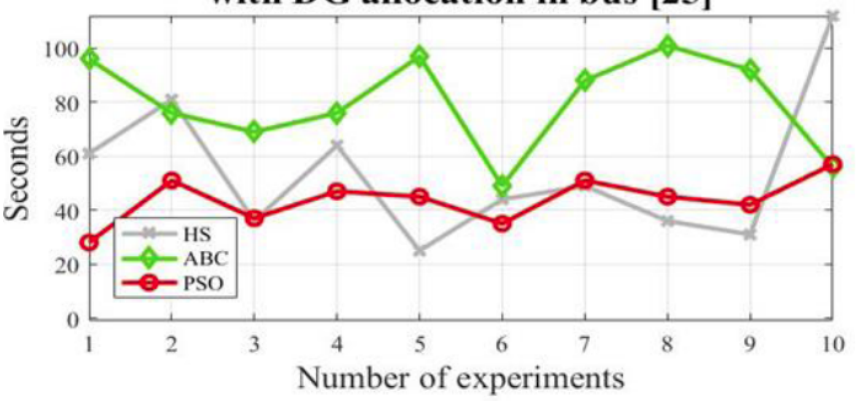

Figure 5: Optimal Iteration and Processing Times, Case-I and Case-II.

In Case-II, all methods install DG on bus 25. DG sizing was not the maximum capacity to make the voltage profile at the bus meet the minimum active power loss. DG sizing in the HS gives $1,911.07 \mathrm{~kW}$ ( $\sigma=51.0407$ ), while the ABC and PSO could achieve $1,762.36 \mathrm{~kW}(\sigma=0.0000)$. In terms of active power loss reduction, the $\mathrm{ABC}$ and $\mathrm{PSO}$ can improve both cases equal to $84.97 \mathrm{~kW}(\sigma=0.0000)$. In term of the optimal iteration and processing time, the PSO had the best performance at 42.00 seconds ( $\sigma=7.7876)$, as shown in Figure 5.

In contrast, the $\mathrm{ABC}$ and PSO had better results in processing, especially PSO. In the first section, the PSO had the best performance. In the second experimental section, only PSO is selected in the Case-III and Case-IV. The empirical model was based on the previous parameter values of tolerance and the 
Table 3: Results of Experiments with PSO, Case-III and Case-IV

\begin{tabular}{|c|c|c|c|c|}
\hline \multirow[t]{2}{*}{ Performance indicators } & \multicolumn{2}{|c|}{$\begin{array}{c}\text { Case-III: } \\
\text { DG allocation buses } \\
{\left[\begin{array}{ll}8 & 30\end{array}\right]}\end{array}$} & \multicolumn{2}{|c|}{$\begin{array}{c}\text { Case-IV: } \\
\text { DG allocation buses } \\
{\left[\begin{array}{lll}8 & 24 & 31\end{array}\right]}\end{array}$} \\
\hline & Mean & $\sigma$ & Mean & $\boldsymbol{\sigma}$ \\
\hline Active power loss (kW) & 70.56 & 0.0000 & 52.29 & 0.0000 \\
\hline DG sizing $(\mathrm{kW})$ & [920.74 1000.00] & - & [899.42 994.48962 .50$]$ & - \\
\hline Optimal iteration (cycles) & 45.56 & 7.3492 & 69.78 & 10.4350 \\
\hline Optimal time (seconds) & 48.34 & 9.9009 & 71.79 & 10.3602 \\
\hline Active power loss (kW) & 70.56 & 0.0000 & 52.29 & 0.0000 \\
\hline
\end{tabular}

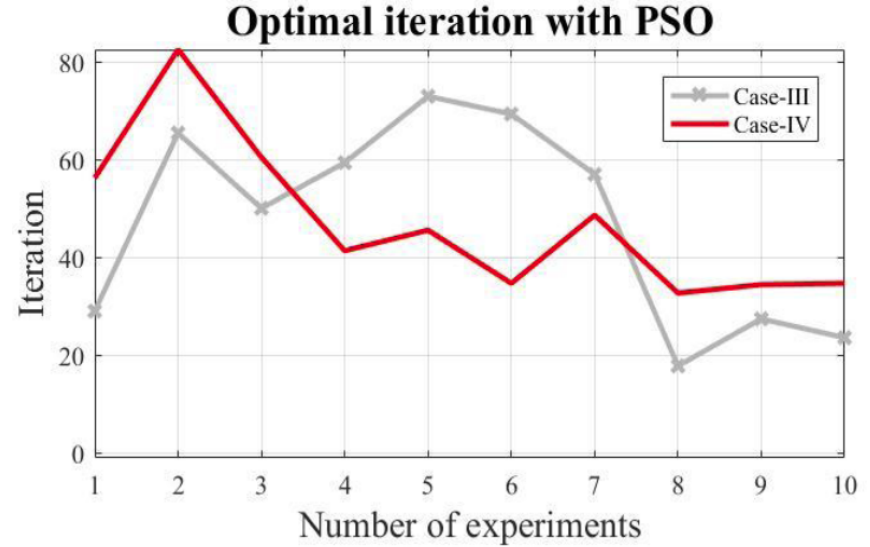

Figure 6: Optimal Iteration and Processing Time with PSO.

number of required iterations. The experiment was conducted 10 times, with results as shown in Table 3.

In Case-III, DG was installed in buses 8 and 30, with total sizing of 920.74 and $1,000.00 \mathrm{~kW}$. The mean active power loss was $70.56 \mathrm{~kW}(\sigma=0.0000)$. In terms of the processing performance, the number of optimal iterations and processing time were 45.56 cycles $(\sigma=7.3492)$ and 48.34 seconds $(\sigma=9.9009)$, respectively, as shown in Figure 6.

In the final Case-IV, the results showed the DG allocation will be installed in buses 8, 24 and 31, with sizing 899.42, 994.48, and $962.50 \mathrm{~kW}$, respectively. The active power loss was reduced to $52.29 \mathrm{~kW}$ $(\sigma=0.0000)$. In terms of efficiency, the optimal iteration and processing time were 69.78 cycles ( $\sigma=10.4350)$ and 71.79 seconds ( $\sigma=10.3602$ ), respectively.

In comparison, the results in Case-III and Case-IV determined the allocation and sizing exactly. In contrast, the value of the optimal iterations and processing time were not stable, due to the $\sigma$ value. In addition to defining the objective function, minimizing active power loss can be achieved effectively. In the

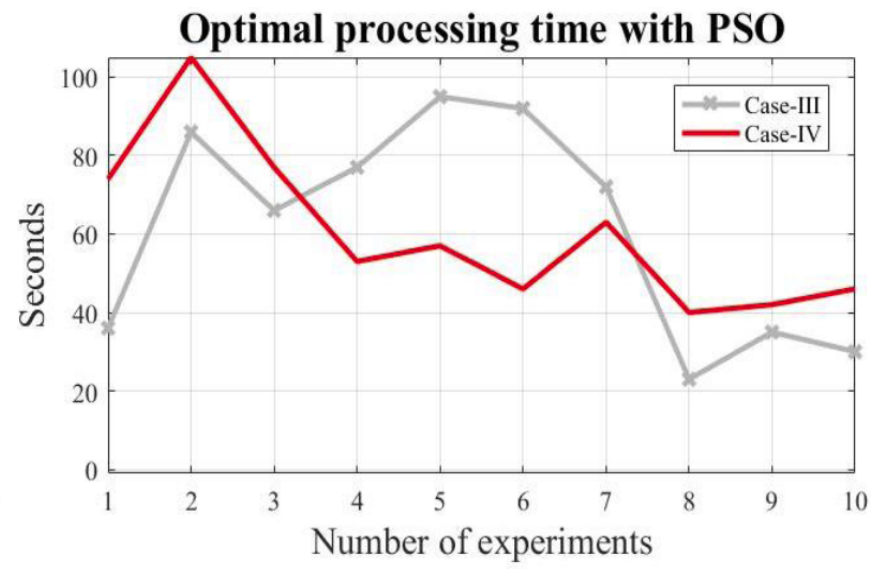

best case, the process of feeder routing and optimization of the DG allocation, and sizing in CaseIV, the active power loss was reduced from 202.67 to $52.29 \mathrm{~kW}$, representing $74.20 \%$.

The steps of minimal active power loss from feeder routing were reduced to $139.56 \mathrm{~kW}$, with DG allocation and sizing by PSO reduced to $52.29 \mathrm{~kW}$, as shown in Figure 7. The results of minimal active power loss can also reduce the overall power consumption. The methods with a reduction of power loss also reduced the maximum power generation capacity from renewable energy.

\section{CONCLUSION}

The paper analyzed active power loss problems, and found a variety of possible solutions. The solution of feeder routing with Adjusting Dijkstra's Cost method, consequently DG allocation and sizing with PSO, also reduced the active power loss. The approach of feeder routing with Dijkstra's algorithm can be applied to adjusted cost in the concept of dynamics to match real power flows. After adjusting the cost, the experimentation was reconfigured as feeder topology 


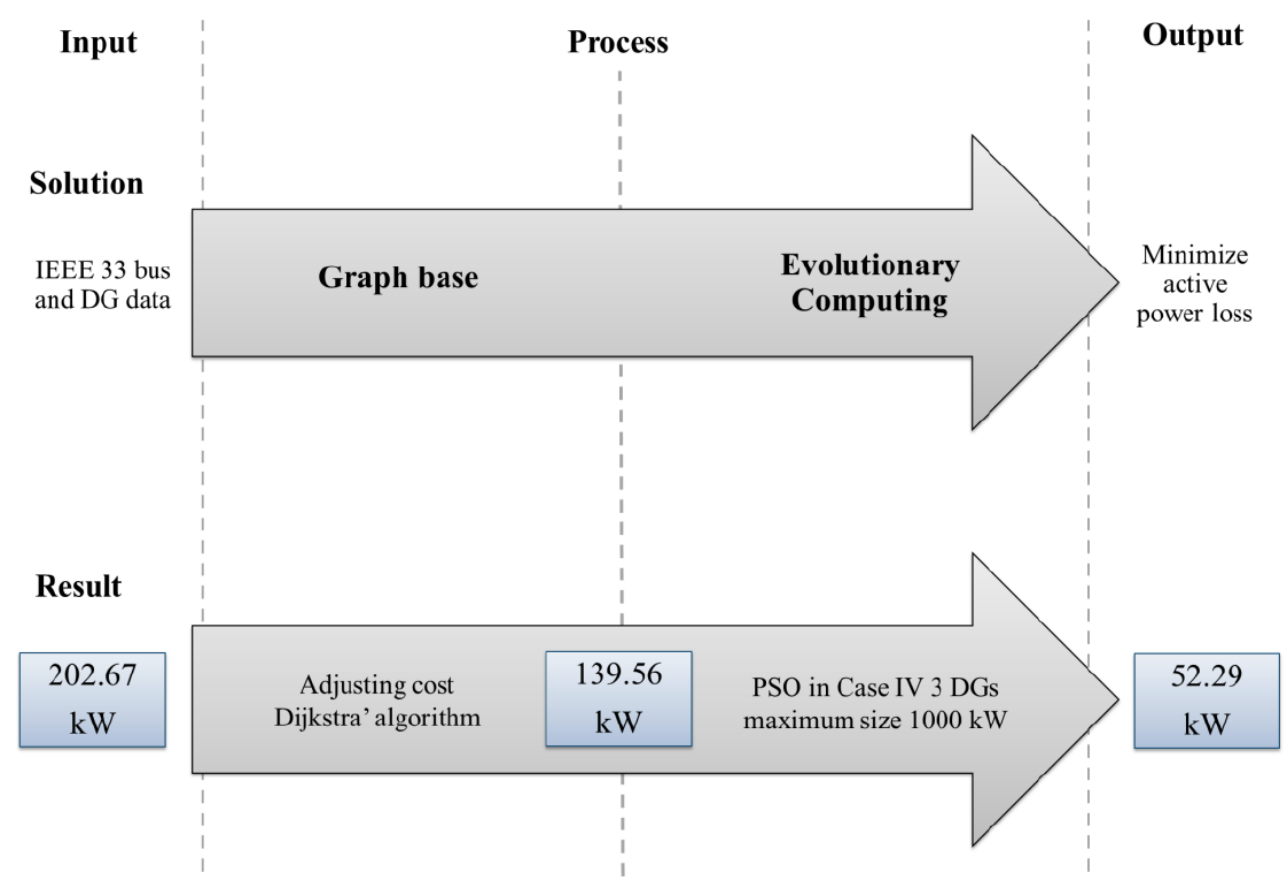

Figure 7: Optimal Active Power Loss for Each Method.

to improve performance. Consequently, DG allocation and sizing was conducted by Evolutionary Computing for reducing active power loss.

The experiments found that PSO could determine the proper location and sizing of DG. Both methods have been able to solved the active power loss problem in a coherent system. The research can be extended to cover a multi-objective function by adding a Power Factor for more effective measurement. Furthermore, the experimental data can be adjusted to time series, with historical loads and supplies from real feeders.

\section{ACKNOWLEDGEMENT}

The authors wish to thank Chia-Lin Chang and Michael McAleer for helpful comments and suggestions.

\section{REFERENCES}

Abdel-Akher M. (2013), Voltage Stability Analysis of Unbalanced Distribution Systems Using Backward / Forward Sweep Load-Flow Analysis Method with Secant Predictor, IET Generation, Transmission \& Distribution, 7, 309-317. https://doi.org/10.1049/iet-gtd.2012.0360

Alafnan H., Zhao J., Ma W. 2016. Prevention of overvoltage induced by large penetration of photovoltaics in distribution networks by electric vehicles, IEEE Transportation Electrification Conference and Expo, Asia-Pacific, 2016, pp. 525-530. https://doi.org/10.1109/itec-ap.2016.7513010

Aswini E., Seshu M. (2016), Placement of Renewable Distributed Generation Using Harmony Search Optimization Technique,
International Journal of Innovative Research in Science Engineering and Technology, 5, 1914-1924.

Baran M. E., Wu F. F. (1989), Network Reconfiguration in Distribution Systems for Loss Reduction and Load Balancing, IEEE Transactions on Power Delivery, 4(2), 1401-1407. https://doi.org/10.1109/61.25627

Esmaeilian H. R., Fadaeinedjad R. (2015), Energy Loss Minimization in Distribution Systems Utilizing an Enhanced Reconfiguration Method Integrating Distributed Generation, IEEE Systems Journal, 9, 1430-1439. https://doi.org/10.1109/JSYST.2014.2341579

Fahad A., Mohamed E. (2009), Modified Artificial Bee Colony Algorithm for Optimal Distributed Generation Sizing and Allocation in Distribution Systems, Electrical Power and Energy Conference, 2009, pp. 1-9.

Farhadi P., Ghadimi N., Sojoudi T. (2013), Distributed Generation Allocation in Radial Distribution Systems Using Various Particle Swarm Optimization Techniques, Przegląd Elektrotechniczny, 89, 261-265.

Guerriche K. R., Bouktir T. (2015), Optimal Allocation and Sizing of Distributed Generation with Particle Swarm, Revue des Sciences et de la Technologie, 6, 59-69.

Huang X., Zhang Y., Huang H. (2014), Automatic Reactive Power Control in Distribution Network Based on Feeder Power Factor Assessment, IEEE Region 10 Symposium, Indonesia, pp. 1-4.

Jena S., Chauhan S. (2016), Solving Distribution Feeder Reconfiguration and Concurrent DG Installation Problems for Power Loss Minimization by Multi Swarm Cooperative PSO Algorithm, Proceeding of the IEEE/PES Transmission and Distribution Conference and Exposition, July 2016, pp. 1-9. https://doi.org/10.1109/tdc.2016.7520021

Jha, P., Vidyasagar, S. (2013), Dijkstra Algorithm for Feeder Routing of Radial Distribution System, IOSR Journal of Engineering, January 2013, 1-6.

Priya P. S., Reddy C. K. (2013), Optimal Placement of the DG in Radial Distribution System to Improve the Voltage Profile, International Journal of Science and Research (IJSR), 4, 2310-2315. 
Rao R. S., Ravindra K., Satish K., Narasimham S.V.L. (2013), Power Loss Minimization in Distribution System Using Network Reconfiguration in the Presence of Distributed Generation, IEEE Transactions on Power Systems, 28, 317-325. https://doi.org/10.1109/TPWRS.2012.2197227
Tolabi H, B., Ali M. H., Rizwan M. (2015), Simultaneous Reconfiguration, Optimal Placement $f$ DSTATCOM, and Photovoltaic Array in a Distribution System Based on FuzzyACO Approach, IEEE Transactions on Sustainable Energy, 6, 210-218.

https://doi.org/10.1109/TSTE.2014.2364230

Received on 16-02-2017 Accepted on 13-05-2017

Published on 09-06-2017

DOI: https://doi.org/10.6000/1929-7092.2017.06.26

(C) 2017 Phawanaphinyo et al.; Licensee Lifescience Global.

This is an open access article licensed under the terms of the Creative Commons Attribution Non-Commercial License (http://creativecommons.org/licenses/by-nc/3.0/) which permits unrestricted, non-commercial use, distribution and reproduction in any medium, provided the work is properly cited. 